\title{
Contribuições do PIBID para o ensino de ciências: Ação-Reflexão- Ação em uma escola pública de Manaus/ Am
}

\author{
Contributions of the PIBID to the teaching of sciences: Action- \\ Reflection-Action in a public school from Manaus/ Am, Brazil
}

\author{
Ana Lúcia Drumond Tanaka ${ }^{1}$ | anadrumond87@hotmail.com \\ Ribamar Alves Ramos ${ }^{1}$ \\ Cinara Calvi Anic ${ }^{1}$
}

\section{RESUMO}

Este artigo visa enfatizar a relevância do PIBID para alunos da Educação Básica. A pesquisa quantitativa objetivou relatar a investigação sobre como a política do PIBID está favorecendo a integração dos bolsistas com os alunos, considerando as percepções destes sobre a execução de atividades do PIBID. O estudo se baseou em observar a interação de alunos do $6^{\circ}$ ano durante a aplicação de um jogo desenvolvido pelos bolsistas do PIBID e análise dos dados coletados através de questionário fechado. Os resultados mostraram que a maioria dos alunos notaram e aprovaram as mudanças durante as aulas de Ciências, o que ocasionou aumento do interesse e envolvimento deles, bem como a valorização do Ensino de Ciências. (CAPES).

Palavras-chave: PIBID; ensino-aprendizagem; Ensino de Ciências.

\section{ABSTRACT}

This article aims at emphasizing the importance of PIBID for Basic Education students. Quantitative research aimed to report the investigation on how policy PIBID is favoring the integration of scholarship with students, considering the perceptions on the implementation of these activities PIBID. The study was based on observing the interaction of the 6th year students during the application of a game developed by fellows PIBID and analysis of data collected through questionnaire closed. The results showed that most students noted and approved the changes during science classes, which led to increased interest and their involvement, as well as the appreciationof Science Teaching. (CAPES)

Key Words: PIBID; teaching and learning; Science Education. 


\section{INTRODUÇÃO}

Percebe-se hoje que os cursos de formação de professores apontam para novos caminhos que revelam uma ruptura com as práticas tradicionais e avança em direção a uma ação pedagógica interdisciplinar voltada para a eficiente formação profissional do licenciando. Isso requer desse profissional um olhar além de suas perspectivas pessoais e profissionais. Segundo Freire (1996) o professor que não leva a sério sua formação, que não estuda e não se esforça para estar à altura de sua tarefa, não tem força moral para coordenar as atividades de sua classe. Diante disso, destaca-se a importância de buscar ferramentas de qualificação e aperfeiçoamento durante e após a formação do professor.

O Programa Institucional de Bolsa de Iniciação à Docência - PIBID tem como objetivo a concessão de bolsas de iniciação à docência para alunos de cursos de licenciatura e para coordenadores e supervisores responsáveis institucionalmente pelo Programa. Um dos objetivos do PIBID é a elevação da qualidade das ações acadêmicas voltadas à formação inicial de professores nos cursos de licenciatura das instituições públicas de educação superior, assim como a inserção dos licenciandos no cotidiano de escolas da rede pública de educação, o que promove a integração entre educação superior e educação básica. O programa visa também proporcionar aos futuros professores a participação na criação de estratégias metodológicas inovadoras para o ensino de Ciências.

Objetivamos, com este trabalho relatar, parcialmente, alguns aspectos da investigação acerca de como o processo vivenciado no PIBID está possibilitando aos licenciandos bolsistas do curso de Ciências Biológicas do Projeto Uirapuru- PIBID- CAPES do Instituto Federal de Educação, Ciência e Tecnologia do Amazonas- IFAM sua integração com os professores da rede pública de ensino e com os alunos de educação básica, considerando as percepções preliminares destes a respeito do desempenho das atividades do PIBID no processo de ensino -aprendizagem em escolas da rede pública de ensino da cidade de Manaus/ AM. Este estudo foi realizado com alunos do $6^{\circ}$ ano do ensino fundamental de uma escola- campo participante do Programa cuja faixa etária varia dos 10 aos 12 anos.

\section{OBJETIVOS}

\section{Geral}

Relatar aspectos acerca de como o processo vivenciado no PIBID está possibilitando a integração dos licenciandos bolsistas com os professores da rede pública de ensino e com os alunos da educação básica durante as aulas de Ciências.

\section{Específicos}

- Destacar a representatividade do PIBID para o Ensino de Ciências;

- Relatar a prática docente através das ações do PIBID;

- Refletir sobre as necessidades de ensinar conteúdos de forma significativa a fim de auxiliar os estudantes a construírem seus próprios conhecimentos.

\section{METODOLOGIA}

O presente estudo é uma análise qualitativa descritiva, na medida em que se desejou extrair a visão crítica dos alunos no que tange o interesse, relevância e importância das atividades desenvolvidas pelo PIBID durante as aulas de Ciências. 
Segundo Ludke (2003), a pesquisa qualitativa tem um ambiente natural como sua fonte direta de dados e o pesquisador como seu principal instrumento; envolve a obtenção de dados descritivos, no contato direto com o do pesquisador e a situação estudada, enfatizando mais o processo do que o produto e se preocupa em retratar as perspectivas dos participantes. Sendo assim, os objetos de estudo da pesquisa formam o tripé: escola, como sendo o ambiente natural da pesquisa, os alunos e a professora de Ciências, estes últimos sujeitos no processo de ensino- aprendizagem.

A investigação deu-se em dois momentos. No primeiro momento, observou-se a interação dos alunos durante a aplicação de uma atividade prática do Programa. Nesta atividade, os alunos participaram de um jogo da memória sobre os grandes biomas do mundo, haja vista ser esse um dos conteúdos ministrados no $6^{\circ}$ ano na escola participante do Projeto Uirapuru/ Programa PIBID e um dos conteúdos previstos nos Parâmetros Curriculares Nacionais (BRASIL, 1996) para o Ensino Fundamental.

Para confeccionar o jogo, foram utilizadas figuras em pares iguais que representavam os sete biomas do mundo. Com papel catão e papel contact, as figuras foram emolduradas e plastificadas. Presas com barbante e enumeradas de um à quatorze, as figuras foram penduradas em um quadro feito de TNT (Figura 1). A dinâmica do jogo aconteceu da seguinte forma: Reunidos em sete equipes de seis alunos cada, os alunos deveriam acertar as figuras iguais que representavam o mesmo tipo de bioma e identificá-lo. À medida que acertavam as figuras, as equipes ganhavam um ponto e, se acertassem o nome do bioma, ganhavam mais um ponto. No final, a equipe que somou mais pontos venceu o jogo. Um trabalho desta natureza, no dizer de Souza (1996) procura: “apresentar às crianças novos instrumentos, recursos que busquem auxiliá-las a pensar, para comparar as informações trazidas para instrumentos diferentes e planejar modos de utilização daqueles eficazes”. São muitos os benefícios da utilização de jogos como ferramentas de ensino, principalmente, quando agregamos a estes a ideia de construção de conhecimento pelos alunos.

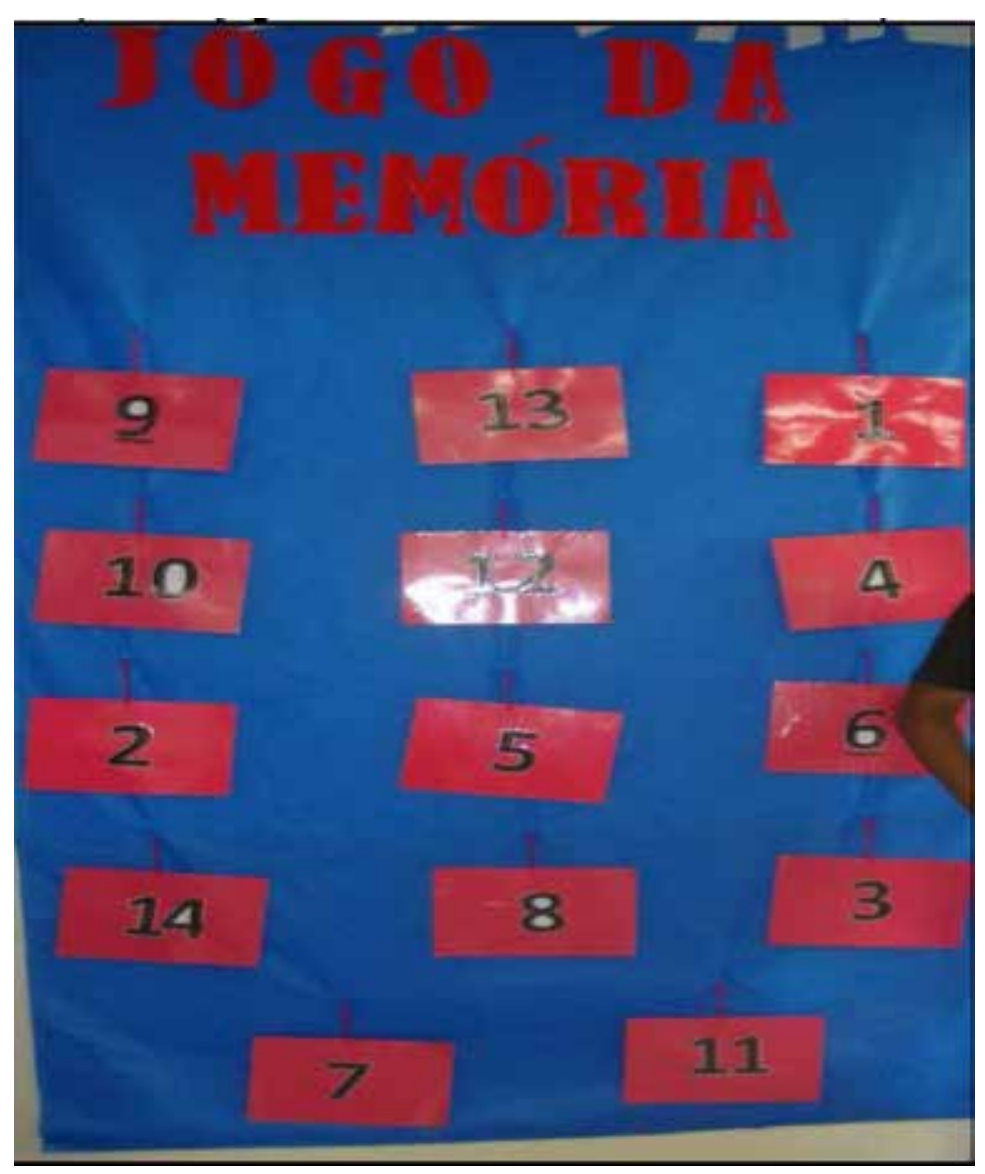

Figura 1: Jogo da memória sobre os Biomas do Mundo. 
No segundo momento foi aplicado um questionário fechado (Tabela 1) para uma amostra de 42 alunos contendo quatro questões objetivas, sendo uma sobre o jogo que havia sido aplicado como referência de atividade do PIBID (Jogo da Memória) e outras três avaliativas sobre o Programa. O uso do questionário foi fundamental para analisarmos de que forma o Programa, através de suas atividades e, consequentemente, os bolsistas estão sendo vistos pelos alunos da escola- campo. Essa pesquisa qualitativa exigiu o contato direto com o ambiente de pesquisa, tanto na observação e na coleta de dados quanto e, principalmente, na análise dos dados.

Tabela 1: Questionário aplicado na pesquisa

\begin{tabular}{|c|c|c|c|c|c|}
\hline $\mathbf{N}^{\mathbf{o}}$ & QUESTÃO & OPÇÃO A & OPÇÃO B & OPÇÃO C & OPÇÃO D \\
\hline 1 & $\begin{array}{l}\text { O que você } \\
\text { achou do Jogo } \\
\text { da Memória } \\
\text { dos Biomas? }\end{array}$ & $\begin{array}{l}\text { Ótimo, pois } \\
\text { conseguimos } \\
\text { aprender o } \\
\text { conteúdo de } \\
\text { forma divertida } \\
\text { sem precisar } \\
\text { decorá-lo. }\end{array}$ & $\begin{array}{l}\text { Bom, pois } \\
\text { conseguimos } \\
\text { entender o que } \\
\text { foi exposto. }\end{array}$ & $\begin{array}{l}\text { Regular, pois } \\
\text { a atividade foi } \\
\text { confusa e não } \\
\text { ajudou a entender } \\
\text { o assunto. }\end{array}$ & Não respondeu \\
\hline 2 & $\begin{array}{l}\text { O que você acha } \\
\text { das atividades } \\
\text { trazidas pelos } \\
\text { bolsistas do } \\
\text { PIBID? }\end{array}$ & $\begin{array}{l}\text { Ótimas, pois as } \\
\text { aulas ficam mais } \\
\text { interessantes e } \\
\text { conseguimos } \\
\text { aprender } \\
\text { brincando. }\end{array}$ & $\begin{array}{l}\text { Boas, mas acho } \\
\text { que poderiam ser } \\
\text { mais criativas } \\
\text { e diferentes. }\end{array}$ & $\begin{array}{l}\text { Regulares, pois } \\
\text { elas não ajudam } \\
\text { a entender o } \\
\text { assunto da aula. }\end{array}$ & Não respondeu \\
\hline 3 & $\begin{array}{l}\text { Como você vê, } \\
\text { hoje, as aulas } \\
\text { de Ciências na } \\
\text { sua escola? }\end{array}$ & $\begin{array}{l}\text { Ótimas, pois } \\
\text { sempre temos } \\
\text { uma atividade } \\
\text { nova (jogo, } \\
\text { vídeo, dinâmica, } \\
\text { etc) após a aula } \\
\text { da professora. }\end{array}$ & $\begin{array}{l}\text { Boas, pois } \\
\text { são aulas bem } \\
\text { divertidas. }\end{array}$ & $\begin{array}{l}\text { Regulares, pois } \\
\text { não gosto das } \\
\text { aulas de Ciências } \\
\text { da minha escola. }\end{array}$ & Não respondeu \\
\hline
\end{tabular}

A valorização do jogo nas escolas surge como uma das iniciativas que podem garantir as condições de ensino e aprendizagem em um ambiente mais eficiente, pois o brincar é uma característica humana, é uma necessidade interior da criança, fonte de prazer e diversão e, ao mesmo tempo, de construção do conhecimento.

Desta forma, o jogo da Memória dos Biomas propõe uma nova maneira de pensar sobre a importância da utilização dos jogos como instrumento pedagógico, uma vez que pôde-se perceber, explicitamente, o envolvimento e empolgação dos alunos durante a atividade proposta.

\section{RESULTADOS E DISCUSSÃO TEÓRICA}

Para análise dos resultados da pesquisa, foram elaborados gráficos de colunas medidos em percentuais de acordo com as respostas dadas às questões propostas no questionário citado.

Nessas questões, procurou-se abordar as dimensões que o Programa alcança no cotidiano dos alunos, desde a atividade mais simples elaborada pelos bolsistas até as mais complexas, na perspectiva de percebermos a importância que as práticas pedagógicas diversificadas durante as aulas de Ciências tem para os alunos. 
Todas as questões foram analisadas sob quatro parâmetros: bom, ótimo, regular ou não respondeu e suas respectivas justificativas.

Na primeira questão, os alunos foram perguntados sobre o que acharam do Jogo da Memória dos Biomas. A maior parte da turma achou ótimo (Figura 2), pois o jogo estimulou a aprendizagem de forma divertida e sem necessitar da velha prática da memorização. Segundo Piaget (1982), o jogo constitui-se em expressão e condição para o desenvolvimento infantil, já que as crianças quando jogam assimilam e podem transformar a realidade. Dessa forma, atrair a atenção dos alunos com a utilização de jogos durante as aulas pode se constituir em um mecanismo de potencialização da aprendizagem e abandono de práticas equivocadas como a memorização de conteúdo.

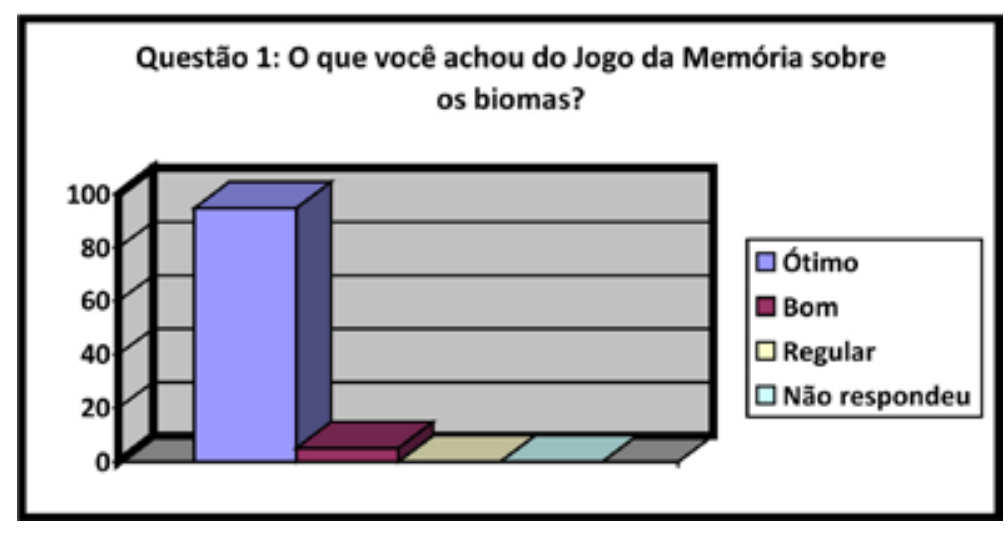

Figura 2: Gráfico referente à questão 1 do questionário.

Na questão 2, os alunos responderam sobre o que acham das atividades trazidas pelos bolsistas do PIBID. Mais uma vez, a maior parte caracterizou as atividades como ótimas (Figura 3), uma vez que tornam as aulas menos monótonas e pode-se aprender brincando. Dessa forma, a escola passa a ser percebida como um espaço por excelência de formação e construção de conhecimentos, além de contribuir para fomentar junto à professora de Ciências práticas pedagógicas diversificadas no que se refere às metodologias de ensino.

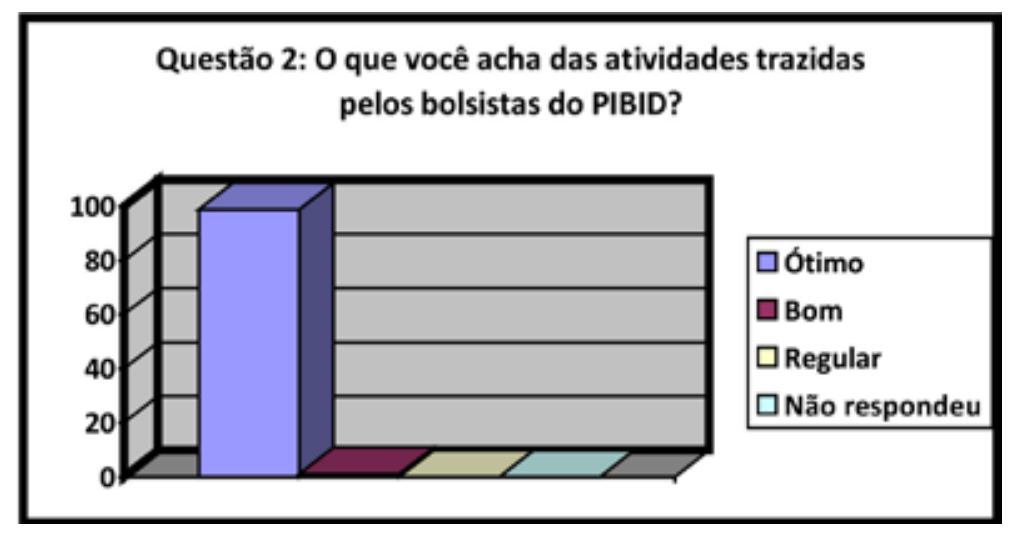

Figura 3: Gráfico referente à questão 2 do questionário.

A terceira e última questão convidou os alunos a avaliarem como percebem as aulas de Ciências na sua escola e as novas formas de aprendizado com as atividades trazidas pelos bolsistas do PIBID em sua turma. As repostas dessa questão foram unânimes em afirmar que as aulas de Ciências são ótimas (Figura 5), pois sempre há uma atividade diferenciada de avaliação após os conteúdos passados pela professora. A inserção do Programa na escola permitiu que alguns conteúdos trabalhados pela professora de Ciências pudessem contar com a interação de objetos pedagógicos novos, o que repercutiu de forma positiva na opinião dos alunos e proporcionou uma maior envolvimento discente durante as aulas de Ciências. 


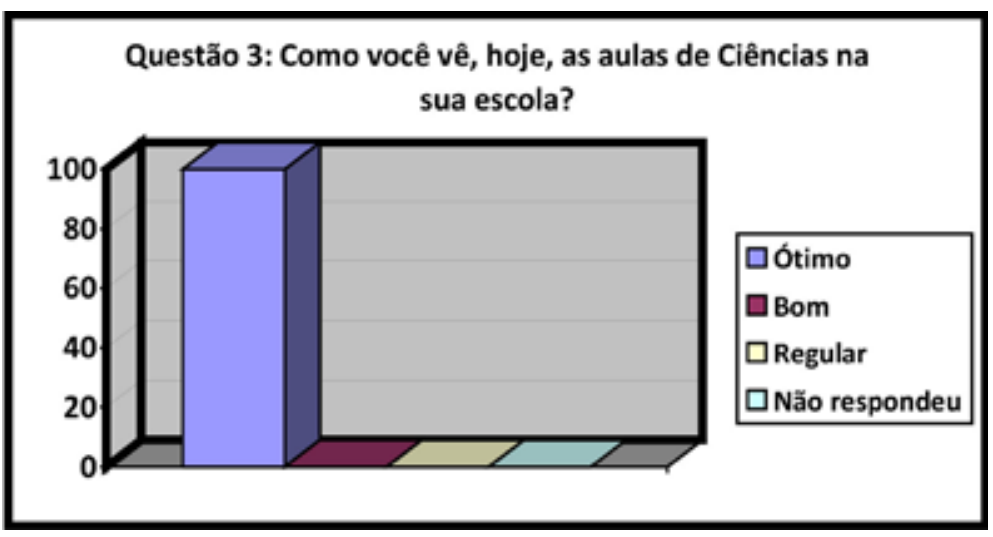

Figura 4: Gráfico referente à questão 4 do questionário.

Os dados acima evidenciam, nitidamente, a representatividade do PIBID durante o processo de ensinoaprendizagem dos alunos. É importante que o professor dê condições para que o aluno possa construir conhecimentos que façam sentido na vida prática dos alunos, pois espera-se que eles venham a intervir como cidadãos na sociedade, sendo críticos e formadores de opiniões.

Acompanhando esta linha de pensamento, Lima (2010) destaca que a formação de professores necessita incorporar formas que não permitam o silenciamento do educando e, consequentemente, de parcela significativa da sociedade. A educação não é feita com alunos alheios ou apáticos, mas sim com aqueles que são envolvidos nas aulas e veem seu interesse despertar a cada nova forma de ensinar que lhe é apresentada.

Percebeu-se, contudo, que o trabalho desenvolvido pelo PIBID busca indicar caminhos possíveis para trabalhar o Ensino de Ciências na escola, assinalando a necessidade de desencadear novas maneiras de pensar a educação, o processo de ensino- aprendizagem e o cotidiano na sala de aula da educação básica ao ensino superior.

\section{CONCLUSÕES}

A realidade da educação básica no Brasil ainda está longe de alcançar o padrão de excelência recomendável, porém não podemos deixar de destacar que iniciativas como o PIBID visam alavancar o nível da educação básica. Segundo o MEC (2011), o PIBID é um dos programas mais relevantes à educação básica atualmente. Ao aproximar a universidade da escola pública, as duas se transformam: o jovem docente adquire experiência e a escola é incitada a repensar seu projeto pedagógico. Ou seja, o PIBID tornou-se um exemplo prático de programas que devem ser estimulados por políticas públicas e aderidos por mais instituições de ensino na educação básica e no ensino superior.

Os resultados obtidos nessa pesquisa mostram que esse Programa apresenta ótima aceitação na escola- campo apresentada. É importante ressaltar que todas as atividades desenvolvidas priorizaram o convívio dos bolsistas na escola, a fim de levá-los a compreender as práticas pedagógicas, as concepções de ensino, as várias atividades que abrangem todo o cotidiano em que estarão atuando, identificando aspectos que requerem novas possibilidades metodológicas, estruturais e humanas para o desenvolvimento da ação docente, superando uma visão tradicional do que é ensinar e aprender. 


\section{REFERÊNCIAS BIBLIOGRÁFICAS}

BRASIL, Leis de diretrizes e bases da educação Nacional. Brasília: MEC/SEF, 1996.

- Parâmetros Curriculares nacionais: Ensino Fundamental.

FREIRE, Paulo. Pedagogia da Autonomia: Saberes necessários à prática educativa. São Paulo: Paz e Terra, 1996.

LIMA, Maria Emilia Caixeta de Castro. Uma formação em Ciências para educadores do campo e para o campo numa perspectiva dialógica. In: CUNHA, Ana Maria de Oliveira et al (orgs.). Convergências e tensões no campo da formação e do trabalho docente. Belo horizonte: Autêntica, 2010. p. 167-183.

LÜDKE, Menga. Pesquisa em educação: abordagens qualitativas - 6a impressão. EPU, 2003.

PIAGET, Jean. O nascimento da inteligência na criança. 4. ed. Rio de Janeiro: Zahar, 1982.

S, Jobim e Souza. (1996). O psicólogo na educação: identidade e (trans)formação. Em M. H. Novaes \& M. R. F. de Brito (Orgs.). Psicologia na educação: articulação entre pesquisa, formação e prática pedagógica. ANPEPP: Teresópolis, V.1, n. 5.

Trecho da entrevista Ministro da Educação Fernando Haddad. Publicado por Assessoria de Imprensa da Capes. Disponível em http://www.capes.gov.br/servicos/sala-de-imprensa/36-noticias/4749-pibid-e-um-dosprogramas-mais-relevantes-a-educacao-basica-atualmente-diz-ministro. Acesso em: 12 jan de 2013. 